\title{
EVALUATION OF COMBINE HARVESTER PARAMETERS USING MANUAL AND AUTO-STEERING MODES
}

\author{
Antanas Juostas, Egle Jotautiene \\ Vytautas Magnus University, Lithuania \\ antanas.juostas@ba-machinery.lt, egle.jotautiene@vdu.lt
}

\begin{abstract}
Automatic steering and other automated control systems for technological processes are widely used in modern intelligent farming systems. Automation of technological processes maximizes the technical potential, shortens the time of technological processes, and reduces the fuel consumption. The installed automatic cruise control systems monitor the set parameters and continuously change the combine speed in the fields based on the data received. The choice of the driving speed is influenced by the following controlled parameters, such as grain separation and cleaning losses, the threshing drum speed, engine load, and the height of the grain mass flow in the feeder house conveyor. The automatic control systems can increase the efficiency of combines by up to $10 \%$. The aim of the study is to analyse the combine harvester operation benefits using manual and auto-steering modes. During the grain harvest, the combine operating data parameters were stored in the microprocessor of the remote monitoring system. During the research, analyses of the combine harvester working time structure, fuel consumption, and other operating data were performed. The analysis of experimental data showed that by using the automatic steering function in straight-ahead driving, the working time for technological operations is used more rationally. The structural analysis of the collected working time data of the combine harvester was performed by the methods of mathematical statistics. It was found that the combine used on average $46 \pm 5 \%$ of the total working time for the technological process. The same analysis of the combine travel time from one field to another, standing due to a full hopper and due to combine failure and other data were analysed. In summary, it can be said that the analysis of the structure of work processes provides detailed information that allows decisions to be made to increase the overall productivity of the machine and to optimize the work processes.
\end{abstract}

Keywords: automatic steering, combine harvester, automated control, cruise control, remote monitoring.

\section{Introduction}

Precision agriculture involves the development and adoption of knowledge-based technical management systems with the goal of optimizing application of fertilizers, chemicals, seeds, and irrigation resources to reduce the input costs and maximize production. Precision agricultural technology has the ability to spatially vary the rates of all inputs to tailor to the varied production potential within the field, which can be gauged by use of geo-referenced historical crop yield data. Variable rate technology (VRT) can be used in both conventional and conservation tillage systems. Adoption of VRT technologies can reduce the fuel consumption, since VRT coupled with Global Positioning Guidance (GPS) system reduces implement overlap during input applications, thus saving working and machine hours [1].

Automatic control and guidance for agricultural vehicles is an important technology to enhance the production efficiency and safety of operations. Automatic guidance systems have been studied for many years. Various guidance technologies in agriculture, including mechanical and optical guidance, satellite navigation and ultrasonic guidance, have been investigated [2]. Precision agricultural technologies like GPS guidance and autosteering systems help reduce overlapping of equipment and tractor passes to save fuel consumption and working time [1]. Global Positioning System receivers are used in agriculture since the early 1990s. Thus, GPS-based guidance technologies studied to automate many field operations such as tillage [3; 4], planting [5], cultivating, and harvesting [6]. Recently, several GPSbased guidance systems commercialized around the world.

Russian firm "Cognitive Agro Pilot" is using computer vision and machine learning for precision guidance. Combines outfitted with a vision-based guidance system that does not require GPS or RTK to operate where fitted into John Deere, New Holland, Claas and Rostselmash combine harvesters. This system detects obstacles, including people, animals, metallic objects and stones along its way, without GPS navigation and RTK positioning. Tied to an artificial intelligence system, the systems provide precision guidance.

The operating systems work with harvesters via CANBUS interface. The internal computer network is used on most farm equipment these days [7]. 
Today, from harvesting to soil preparation, applications that enable the most efficient performance in agriculture rely on state-of-the-art telematics solutions - keeping operators, owners, dealers and manufacturer in touch, every second of the day. As an example, CLAAS telemetry monitors more than 50 relevant parameters from machine settings to the engine speed, fuel consumption to crop yield - all transmitted via the CLAAS communications module linked to a unit's CANBUS.

Connectivity from machine to data platform is critical to delivering 24/7 productivity. The CLAAS communication module houses mobile SIMs. Wireless Logic's SIMs is busy managing data flow from machine to web via the mobile network. From Inverness to Cornwall, Wireless Logic's choice of network operators ensures the right network for the machine's geo-operation, delivering optimal signal strength at all times [8].

TELEMATICS can access all the key information about machine functionality via the internet at any time from any location. This information includes the machine's current location and a comprehensive overview of performance and machine data and service information and conducts an initial diagnostic check.

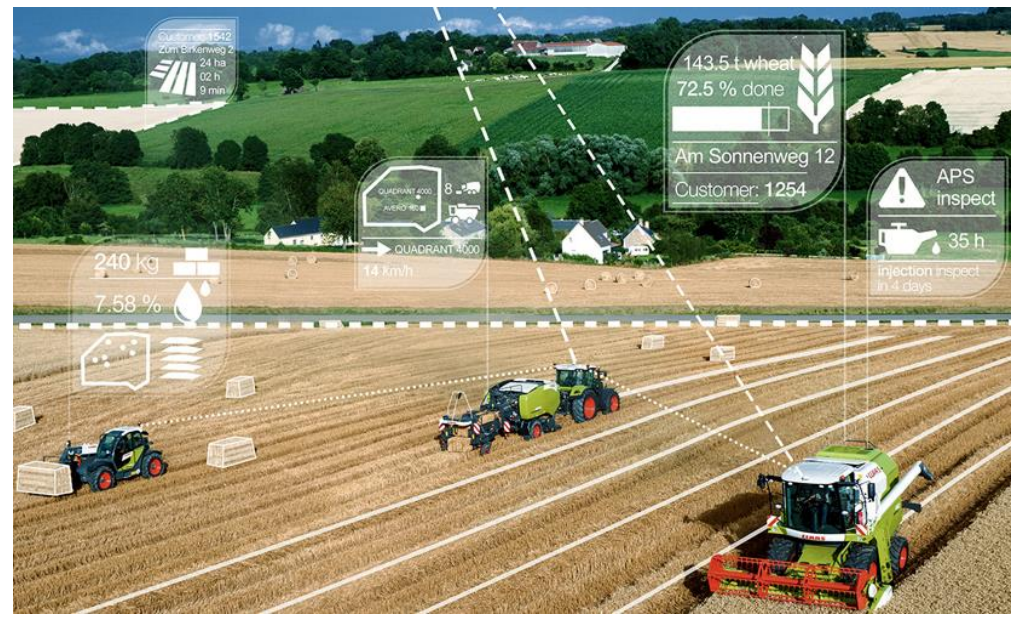

Fig. 1. Working principal of the Telemetry platform [10]

TELEMATICS records data concerning more than 200 different parameters and automatically transmits to the web server at regular intervals via the mobile phone network. The use of telemetry system improves the work processes and allows analyse the operating time. Detailed analysis of the machine performance and adjustment parameters provides machine optimisation possibility. Via TELEMATICS remote diagnostics customers could follow the machine operation hours and plan the maintenance time, which reduces the risk of unexpected machine stop [10].

The aim of the study is to analyse the operation benefits of combine harvesters using manual and auto-steering modes.

\section{Materials and methods}

For the study three Lexion 770 TT (Terra Trac) combine harvesters with the same engine power, automatic steering systems and the same width of cutter bars were selected. The technical parameters of the combine harvesters are presented in Table 1.

Technical parameters of the Lexion 770 Terra Trac combines [9]

Table 1

\begin{tabular}{|l|c|}
\hline \multicolumn{1}{|c|}{ Parameter } & Value \\
\hline Engine, HP & $585(\mathrm{~T} 4)$ \\
\hline Track width, mm & 785 \\
\hline Autosteering & Laser Pilot guidance system \\
\hline Grain tank capacity, 1 & 13500 \\
\hline Cutterbar width, $\mathrm{m}$ & 10.8 Vario \\
\hline
\end{tabular}

The harvested field size varied from 25 to 45 ha. Majority of the winter wheat crop field was standing crop with 16.5 to $18 \%$ of grain moisture. 
Using the data collected and stored on the Claas Telemetry Platform, the winter wheat harvest of 2020 was analysed. Fields of different size and shape were selected for the study. Comparative harvesting was performed with the combine driven with automatic steering engaged and with manual steering, Fig. 2.

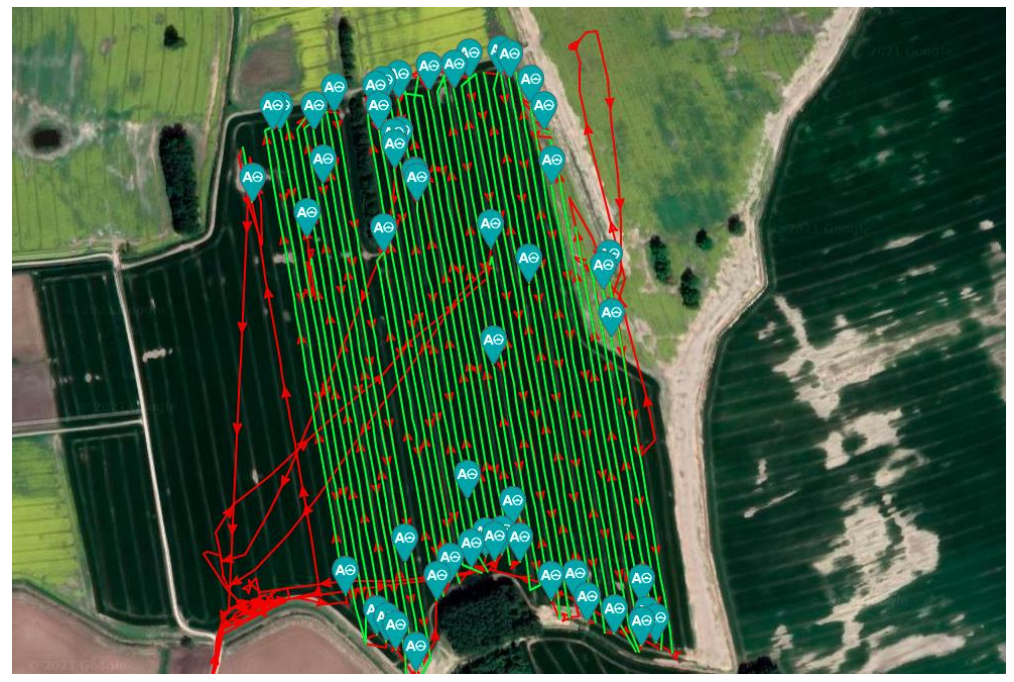

Fig. 2. Automatic steering use during the harvesting process:

For automatic steering, at the harvesting time, the straight lines made during the sowing were used. The combine harvester equipped with optical sensors, named laser pilot, were capable to follow the field tramlines and so ensure straight line harvesting. A straight line driving application allowed grain unloading wagon parallelly follow the combine harvester during grain unloading on its run.

For the analysis, the following combine harvester performance parameters, like the grain tank unloading while the combine stopped or at the harvest process, yield of harvested wheat, driving speed, fuel consumption and others, are presented in Table 2.

Table 2

\section{Harvesting performance data [9]}

\begin{tabular}{|c|c|c|c|c|c|c|c|c|}
\hline \multirow{2}{*}{$\begin{array}{l}\text { Combine } \\
\text { harvester }\end{array}$} & \multirow{2}{*}{$\begin{array}{c}\text { Harvesting } \\
\text { date }\end{array}$} & \multirow{2}{*}{$\begin{array}{l}\text { Harvested } \\
\text { crop }\end{array}$} & \multirow{2}{*}{$\begin{array}{c}\text { Harvested } \\
\text { area, ha }\end{array}$} & \multirow{2}{*}{ 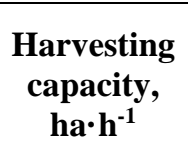 } & \multicolumn{2}{|c|}{$\begin{array}{c}\text { Fuel } \\
\text { consumption }\end{array}$} & \multirow{2}{*}{$\begin{array}{c}\text { Average } \\
\text { crop } \\
\text { yield, } \\
\text { t·ha }{ }^{-1}\end{array}$} & \multirow{2}{*}{$\begin{array}{c}\text { Average } \\
\text { harvesting } \\
\text { speed, } \\
\mathbf{k m} \cdot \mathbf{h}^{-1}\end{array}$} \\
\hline & & & & & l.ha' $\mathbf{h}^{-1}$ & $\mathbf{l} \cdot \mathrm{t}^{-1}$ & & \\
\hline \begin{tabular}{|l|} 
LEX770 No.1 \\
\end{tabular} & 13.08 .2020 & W.wheat & 339.10 & 3.56 & 25.6 & 3.43 & 7.46 & 3.61 \\
\hline \begin{tabular}{|l} 
LEX770 No. 2 \\
\end{tabular} & 02.08 .2020 & W.wheat & 619.66 & 5.00 & 19.8 & 2.90 & 6.83 & 4.75 \\
\hline \begin{tabular}{|l|} 
LEX770 No.3 \\
\end{tabular} & 22.08 .2020 & W.wheat & 352.89 & 4.64 & 21.9 & 2.47 & 8.87 & 4.68 \\
\hline
\end{tabular}

Data are analysed using mathematical statistical methods.

\section{Results and discussion}

For the results discussion it was important to evaluate the economic effect and harvesting performance efficiency of different grain tank unloading phase use: when grain was unloaded during the combine stop and continuing the harvesting operation. One of the analysed parameters of the combine's work efficiency was the distance travelled by the combine when the grain was unloaded while driving.

The visual distance graph of the combine driving route provided on the telemetry platform was used to determine the distance travelled when unloading grain while the combine was running, Fig. 3.

The red lines in Figure 3 show the combine harvester driving trajectories in the field. The driving lines shown in green indicate that the combine was unloading the grain tank without stopping the harvesting process. At the same time, the length of the tramline marked in green indicates the distance traveled by the combine until the grain tank fully emptied. Using a distance measurement program of the telemetry platform, the five randomly selected combine driving distances, during grain unloading, 
were measured, Fig. 3. The data of the distance traveled when unloading grain without stopping the work process are presented in Table 3. All three investigated combines operated in wheat crop fields.

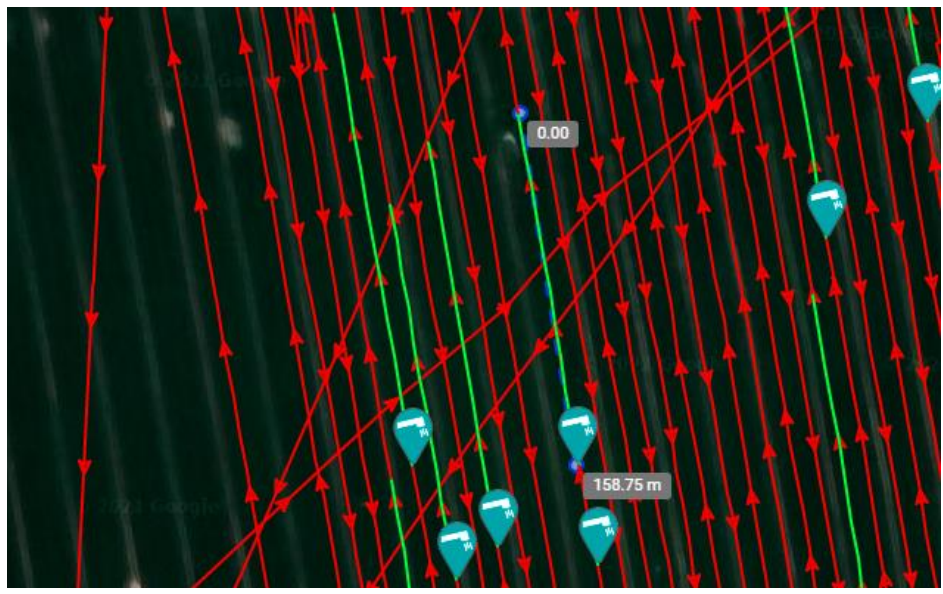

Fig. 3. Grain unloading during combine run (lines marked in green)

The obtained results showed that the length of the traveled distance during the grain unloading process depends not only on the crop yield, but also on the skills of the combine operator.

As it can be seen from the data in Table 2, at the average wheat crop yield of $7.46 \mathrm{t} \cdot \mathrm{ha}^{-1}$, the average driving speed of the combine harvester LEX770 No.1 was only $3.61 \mathrm{~km} \cdot \mathrm{h}^{-1}$, which makes up only $3.56 \mathrm{ha} \cdot \mathrm{h}^{-1}$ of the combine productivy. At the same time, productivity of combine harvesters LEX770 No. 2 and No.3, operated under similar conditions, was 5.00 and 4.64 ha $\cdot \mathrm{h}^{-1}$ respectively, which is higher in productivity by $40.4 \%$ and $30.3 \%$ than LEX770 No.1 combine.

Taking into account the crop yield, operator skills and other criteria, the obtained measurement data showed that the combines selected in the study drove from 111.90 to $179.81 \mathrm{~m}$ without stopping the combine during grain unloading. Meanwhile, every stop of the combine for unloading the grain means a reduction in the work efficiency.

Table 3

Measurement results of distance travelled during unloading grain [9]

\begin{tabular}{|c|c|c|c|c|c|c|}
\hline $\begin{array}{c}\text { Combine } \\
\text { harvester }\end{array}$ & \multicolumn{5}{|c|}{ Driven distance at grain unloading process, m } & $\begin{array}{c}\text { Average distance } \\
\text { driven during } \\
\text { unloading, m }\end{array}$ \\
\hline Measurement & 1st & 2nd & 3rd & 4th & 5th & 111.90 \\
\hline LEX770 No.1 & 104.52 & 115.7 & 116.81 & 116.04 & 106.45 & 179.81 \\
\hline LEX770 No.2 & 170.56 & 182.14 & 157.24 & 199.91 & 189.19 & 147.22 \\
\hline LEX770 No.3 & 160.41 & 168.61 & 123.1 & 137.19 & 146.77 & 147.22 \\
\hline
\end{tabular}

Using the data stored in the telemetry platform (Fig. 4) shows that the grain tank unloading time of the analysed harvesters ranged from 1.75 to $2.25 \mathrm{~min}$. The duration of the grain unloading time and its graphical representation on the telematics platform are shown in Fig. 4.

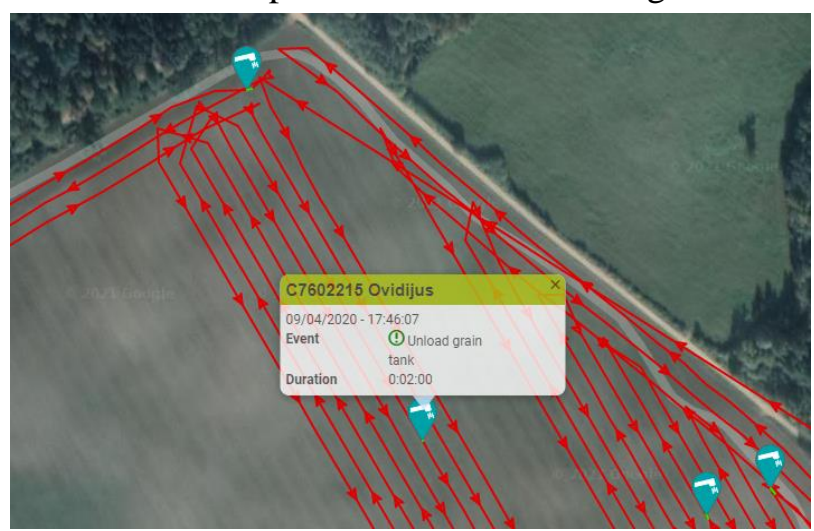

Fig. 4. Duration of grain unloading time when the combine stopped 
The graph also shows the combine serial number, harvest date, and grain unloading time. With a telemetry platform the farmer can easily see not only the number and place of grain unloads in a given field, but also whether the grain was unloaded while the combine was running or not. At a stopped combine, the grain tank unloading on average takes about 2 minutes. That is maybe not much, if we count one stop. However, if the yield is high, there are more than tens of such stops for grain unloading in one field.

Analyzing the data presented on the telemetric platform, it can be seen that the combine harvesters unloaded from 268 to 448 unit of grain tanks during the whole wheat harvest in 2020. That means, if the grain unloading would be performed by stopping the combine, it can take from 8.93 to $14.93 \mathrm{~h}$ of inefficiently spent harvesting time.

1700

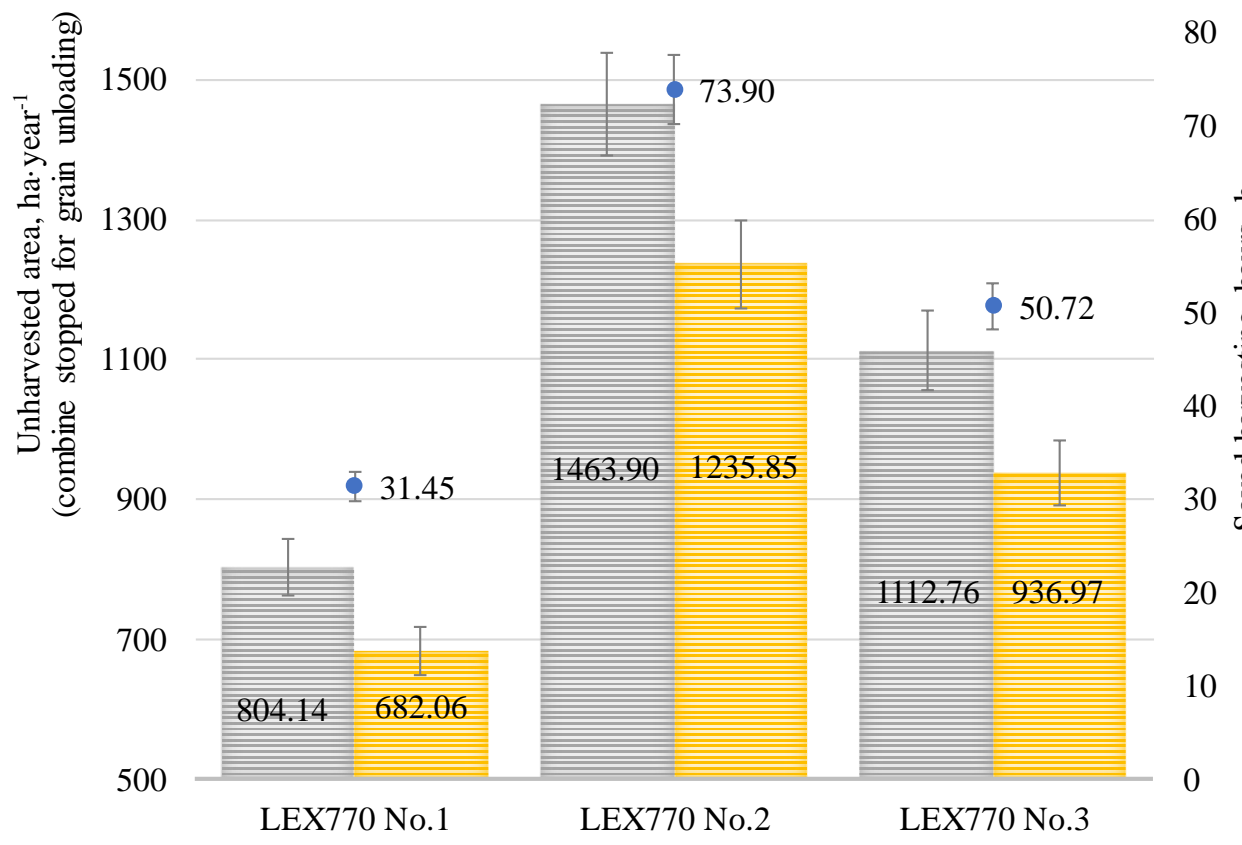

90

80

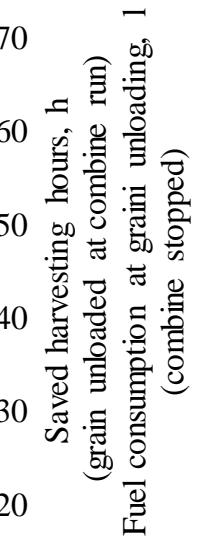

0

Fig. 5. Time, fuel consumption and unharvested area dependencies on the grain unloading process

Unloading grain during the harvesting process, the combine harvester with $10.8 \mathrm{~m}$ cutter bar additionally could harvest from 0.121 to 0.195 ha of the crop area. According to the data presented in Fig. 5, it can be stated that during the wheat harvest season in addition 32.4 to 87.0 ha could be harvested at grain unloading during the combine run. This would represent between 9.54 and $14.92 \%$ of the total wheat crop area, respectively harvested during the season. In other words, due to the stops for grain unloading, an additional time of 8.83 to $14.78 \mathrm{~h}$ would have to be allocated for the remaining unharvested area, which would result in a combination of 1 to 1.5 days, respectively. Combine harvester stops for grain unloading not only consume time, but also additional fuel. The study has shown that 682.06 to 1235.851 of fuel would be consumed during grain unloading when the combine stopped. Similar results are presented by other authors [11]. In many cases to achieve faster grain unloading the combine engine speed is kept at maximum the same as during harvesting. Most commonly combine stops for grain unloading are used when the combine does not have an automatic steering system. When driving a combine manually, it is much more difficult to keep the straight cut edge of the field. The uneven edge of the field is more difficult to follow for a grain truck, forcing the combine driver to stop the combine for grain unload. The uneven edge of the field not only makes it more difficult to unload grain while driving, but also creates a risk of the vehicle colliding with the cutter bar or the combine itself. There is also a possibility of significant grain losses when the unloaded grain falls not accurately enough into the grain transport trailer. Grain spilled over the side of a transport trailer is a huge financial loss. 


\section{Conclusions}

1. The obtained results showed that the length of the road travelled by the combine depends not only on the yield of the crop, but also on the skills of the operator. The average crop yield when harvesting wheat with the LEX770 No.1 combine was $7.46 \mathrm{t} \cdot \mathrm{ha}^{-1}$, with an average performance capacity of $3.56 \mathrm{ha} \cdot \mathrm{h}^{-1}$. The productivity of LEX770 No.2 and No.3 combine harvesters operating under similar conditions was 5.00 and $4.64 \mathrm{ha} \cdot \mathrm{h}^{-1}$, which is $40.4 \%$ and $30.3 \%$ higher productivity than No. 1 combine, respectively.

2. After the data analysis it can be stated that during the wheat harvest, when the grain is unloaded while driving, in addition it would be possible to harvest from 32.4 to 87.0 ha, respectively. Combine stops for grain unloading would take 8.83 to $14.78 \mathrm{~h}$, this in addition prolongs the harvest from 1 to 1.5 days, respectively.

\section{References}

[1] USDA-NRCS. Conservation practices that save: precision agriculture. 2006. [online] [21.03.2021] Available at http://www.usada.gov.

[2] Reid J.F., Zhang Q., Noguchi N., Dickson M. Agricultural automatic guidance research in North America. Computers and electronics in agriculture, No 25, 2000, pp. 155-167.

[3] Bell T. Automatic tractor guidance using carrier-phase differential GPS. Computers and electronics in agriculture, No 25, 2000, pp. 53-66.

[4] Yukumoto O., Matsuo Y., Noguchi N. Robotization of agricultural vehicles - description of the tilling robot (Part 2). Japan Agricultural Research Quarterly, No 34, 2000, pp. 107-114.

[5] Nagasaka Y., Umeda N., Kanetani Y., Taniwaki K., Sasaki Y. Autonomous guidance for rice transplanting using global positioning and gyroscopes. Computers and electronics in agriculture, No 43, 2004, pp. 223-234.

[6] Iida M., Yamada Y. Rice harvesting operation using an autonomous combine with a GPS and a FOG. Proceedings of the Conference of Automation Technology for Off-road Equipment, ASAE, 2006, pp. 125-131.

[7] Vogt W. New autosteering system works without GPS. 2020. [online] [23.01.2021]. Available at: https://www.farmprogress.com/technology/new-autosteering-system-works-without-gps.

[8] Townson B. Reaping the benefits of M2M. 2021. Available at: https://www.wirelesslogic.com/case-study/claas/

[9] Lectura. Technical specs - Lexion 770 TerraTrac Claas. 2021. [online] [21.03.2021] Available at: https://www.lectura-specs.com/en/model/agricultural-machinery/combine-harvesters-claas/lexion770-terratrac-1162325.

[10] Claas-e-systems. How TELEMATICS works. 2021. [online] [21.03.2021] Available at: https://www.claas-e-systems.com/en/oem-products/telematics/

[11] Benes L. John Deere combine harvesters working parameter's evaluation. Master thesis. Praha, 2013. 